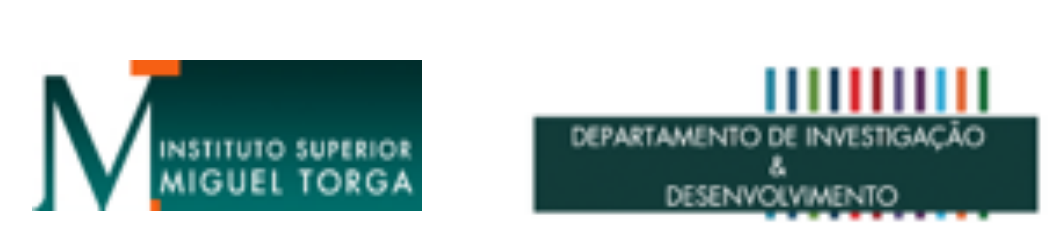

\title{
The temporal evolution of life satisfaction in institutionalized elderly: A longitudinal study
}

Espírito-Santo, H. ${ }^{1}$, Lemos, L. ${ }^{1}$, Simões, S. ${ }^{1}$, Guadalupe, S. 1 \& Daniel, F. 1,2

${ }^{1}$ Miguel Torga Institute, Department of Research \& Development; Coimbra, Portugal, ${ }^{2}$ Centre for Health Studies and Research of the Coimbra University

\section{Introduction}

Subjective well-being in elderly is a major determinant of health and successful aging (Jivraj, Vanhoutte, Nazroo, \& Chandola, 2013; Mhaoláin et al., 2012).

Research shows that variables such as depression, less functionality and health, less contact with family and others, may have a negative impact on life satisfaction (Siedlecki et al., 2008; Tooth et al., 2008; Westaway, Olorunju, \& Rai, 2007).

\section{Objectives}

To verify which variables correlate with satisfaction with life (SWL) and analyze which of them predict the evolution of SWL.

\section{Aims}

To examine correlates and predictors of SWL in institutionalized elderly.

\section{Methods}

This study was a subsidiary longitudinal analysis of the cross-sectional data gathered at Phase I (2010-2012; $n$ = 493 elderly) and after 36 months at Phase II (2013-2014; $n=85)$ of Aging Trajectories Project from Miguel Torga University College. Measures included the Satisfaction with life scale (SWLS; Diener, Emmons, Larsen, \& Griffin, 1985), Geriatric Depression Scale (Yesavage et al., 1983), University of California Los Angeles loneliness scale (Russell, Peplau, \& Ferguson, 1978), and the Geriatric Anxiety Inventory (Pachana et al., 2006).

\section{Results}

At Phase I, higher scores in SWL scale correlated with having visits $(r=0.17 ; p<0.01)$, specially from family $(r=0.20 ; p<0.01)$, less depressive $(r=-0.42 ; p<0,001)$ and anxiety symptoms $(r=-0.25 ; p<0.001)$, less loneliness feelings $(r=-0.37 ; p<0.001)$, less functionality $(r=0.15 ; p<0.01)$, and better general physical health $(r=0.25 ; p<0.001)$.

Age, sex, civil status, cognitive, and executive status did not correlate with SWL.

SWL, depressive and anxiety symptoms, and loneliness feelings were stable through time, between assessment stages $(p<0.01)$.

The worsening of depression and loneliness through time predicted the negative evolution of SWL (respectively, $B=1.16 ; p<0.01 ; B=-0,69 ; p<0.05)$.

\section{Conclusions}

Adding to previous research (Alexopoulos, 2005; Siedlecki et al., 2008; Victor \& Scambler, 2000; Zaninotto, Falaschetti, \& Sacker, 2009), these findings highlight the relevance of early detecting depressed mood and loneliness feelings in life satisfaction of institutionalized elderly, and the importance of the treatment and the development of preventive interventions for this vulnerable population.

\section{References}

\section{Alexopoulos, G. S. (2005). Depression in the elderly. Lancet, 365(9475), 1961-1970.}

Diener, E., Emmons, A., Larsen, R. J., \& Griffin, S. (1985). The satisfaction with life scale: A measurement of life satisfaction. Journal of Personality Assessment, 49, 71-75.

Jivraj, S., Vanhoutte, B., Nazroo, J., \& Chandola, T. (2013). Age, ageing and subjective wellbeing. Manchester, UK: CCSR, University of Manchester.

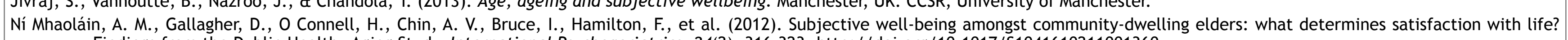
Findings from the Dublin Healthy Aging Study. International Psychogeriatrics, 24(2), 316-323. http://doi.org/10.1017/S1041610211001360

Pachana, N. A., Byrne, G. J., Siddle, H., Koloski, N., Harley, E., \& Arnold, E. (2006). Development and validation of the Geriatric Anxiety Inventory. International Psychogeriatrics, 19(01),103.

Russell, D., Peplau, L., \& Ferguson, M. (1978). Developing a measure of loneliness. Journal of Personality Assessment, 42, 290-294.

Siedlecki, K. L., Tucker-Drob, E. M., Oishi, S. \& Salthouse, T. A. (2008). Life satisfaction across adulthood: different determinants at different age?. The Journal of Positive Psychology, 3(3), $153-164$.

Tooth, L., Russell, A., Lucke, J., Byrne, G., Lee, C., Wilson, A., \& Dobson, A. (2008). Impact of cognitive and physical impairment on carer burden. Quality of Life Research, $17,267-273$.

Victor, C.R. \& Scambler, S. (2000). Being alone in later life: Loneliness, social isolation and living alone. Reviews in Clinical Gerontology, $10,407-417$.

Vidarsdottir, H., Fang., F., Chang, M., Aspelund, T., Fall, K., Jonsdottir, M., Jonsson, P., Cotch, M., Harris, T., Launer, L., Gudnason, G., \& Valdimarsdottir., U. (2014). Spousal Loss and Cognitive Function in Later Life: A 25-Year Follow-up in the AGES Reykjavik Study. American Journal of Epidemiology, 179(6), 674-683.

Westaway, M. S., Olorunju, S. A., \& Rai, L.-C. J. (2007). Which personal quality of life domains affect the happiness of older South Africans? Quality of Life Research, 16, 1425-1438.

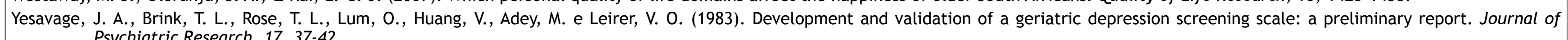
Psychiatric Research, 17, 37-42.

Zaninotto, P., Falaschetti, E., \& Sacker, A. (2009). Age trajectories of quality of life among older adults: results from the English Longitudinal Study of Ageing. Quality of Life Research, 18(10), 1301-1309. doi:10.1007/s11136-009-9543-6. 